\title{
GH dependence and GH withdrawal syndrome in GH treatment of short normal children: evidence from growth and cardiac output
}

\author{
Meir Lampit, Abraham Lorber ${ }^{1}$, David L Vilkas ${ }^{1}$, Tova Nave and Ze'ev Hochberg \\ Divisions of Endocrinology and ${ }^{1}$ Cardiology, Department of Pediatrics, Rambam Medical Center, Haifa, Israel \\ (Correspondence should be addressed to Z Hochberg, Faculty of Medicine, Technion, POB 9649, Haifa 31096, Israel
}

\begin{abstract}
The child's age is a significant determinant of the outcome of GH therapy; prepubertal children respond better on both short term and long term growth, whereas adolescents tend to accelerate their bone maturation more than growth. The present study was designed to evaluate the efficacy of an interrupted GH therapy protocol of young, short normal children. GH was given for a period of 3 years, or until they reached the 25th percentile, then discontinued at a young age (not more than 9 years), and then the children's growth followed until final height. Yet, after discontinuation of GH therapy, growth came close to a complete stand-still. The present report focuses on describing the period beyond GH withdrawal and its impact on growth and cardiac performance. Twenty-two children received daily s.c. injections of $0.9 \mathrm{mg} / \mathrm{m}^{2} \mathrm{hGH}$ and 12 children were the control, untreated group. Growth and echocardiography were followed during therapy and 2 years thereafter. During GH treatment growth velocity accelerated markedly over the first year; it slowed down over the second and third years, and decelerated after GH withdrawal to a velocity that was significantly lower than pretreatment values. Growth rate remained low for the next year, and recovered to pretreatment velocity by the fourth semiannual measurement. To evaluate the role of the GH-IGF-I axis during the growth deceleration, serum IGF-I, insulin-like growth factor-binding protein-3 (IGFBP-3), and an arginine stimulation test were performed at 1, 3 or 6 months after GH withdrawal, and compared with pretreatment response. GH response was $70 \%$ of pretreatment values by 1 month and recovered completely by 3 months post treatment. Serum IGF-I and IGFBP-3 levels were normal throughout. End-systolic and end-diastolic left ventricular dimensions as well as cardiac output did not change during the 2 year course of GH therapy, but fell significantly during the initial 6 months of GH withdrawal. Thus, daily injections of GH to prepubertal short normal children is associated with development of drug dependence, followed during the abstinence period by deceleration of growth and reduction of cardiac output to levels that are lower than pretreatment values. After GH therapy for 30-36 months the withdrawal syndrome persists for 18 months, and is not induced by alterations of serum levels of GH or IGF-I.
\end{abstract}

European Journal of Endocrinology 138 401-407

\section{Introduction}

The controversy about growth hormone $(\mathrm{GH})$ therapy of idiopathic short stature (ISS) consists of dilemmas on the definition of normal stature, the social approach, ethics and economical considerations (1). All these need to be based on factual grounds of the potential benefit and possible risks of such therapy. During 1-4 years of GH therapy, short children increase their growth rate and height standard deviation score (SDS) similar to the response seen in classical GH deficiency (GHD) (1-4). The long term results are variable, with reports of no increase in the final height $(5,6)$, a small increase $(7)$, or a marked increase $(8,9)$. As the collaborative Israeli study of efficacy and safety of $\mathrm{GH}$ therapy was analyzed (10), we realized that in 65 boys with GHD or neurosecretory dysfunction, aged 3-15 years, treated with 3 times weekly $0.1 \mathrm{mg} / \mathrm{kg}$ s.c. $\mathrm{GH}$, the child's age was the most significant determinant of therapy outcome; boys of the prepubertal age group gained over the course of 3 years an average $8 \mathrm{~cm}$ of predicted adult height, pubertal boys over the age of 12 years showed a negative correlation of their predicted height gain against age, and boys over the age of 14 years showed a loss of predicted height during $\mathrm{GH}$ therapy.

The present study was, therefore, designed to evaluate the efficacy of GH therapy in an interrupted protocol of young ISS children, i.e. to treat them with $\mathrm{GH}$ for a period of 3 years or until they reached the 25 th 
percentile, to discontinue therapy at a young age (no more than 9 years), and to follow growth until final height.

As evidence is accumulating that $\mathrm{GH}$ is a physiological regulator of myocardial growth and performance (11), an echocardiography follow-up was added to the protocol.

The short term response to therapy was positive, as expected, and growth will be followed until final height. Yet, after interruption of GH therapy, growth came close to a complete stand-still.

The present report focuses on a description of the period after GH withdrawal and its impact on growth and cardiac performance.

\section{Patients and methods}

Thirty-four ISS children, aged 2-6 years were studied. Criteria for ISS were: height less than -2 SDS; growth rate more than -1 SDS; bone age less than $75 \%$ of chronological age; and serum GH concentration on an arginine stimulation test more than $10 \mu \mathrm{g} / \mathrm{l}$.

Twenty-two children received daily s.c. injections of hGH (BioTropin, BioTechnology General Ltd, Rehovot, Israel) at a dose of $0.9 \mathrm{mg} / \mathrm{m}^{2}$ surface area. Twelve children were the control, untreated group. The control group were children who were referred by their parents to the growth clinic, but did not wish to receive $\mathrm{GH}$ therapy. The clinical characteristics of the treated group and the controls are summarized in Table 1 . The protocol was approved by the Helsinki Committees of the Rambam Medical Center and the Israel Ministry of Health. Consent was obtained from the parents. Treatment was continued until the child reached the 25 th percentile, but no longer than 3 years. The children were measured at 3-month intervals, bone age was assessed yearly (by the Greulich and Pyle method), as were serum insulin-like growth factor-I (IGF-I), insulinlike growth factor-binding protein-3 (IGFBP-3) and alkaline phosphatase. Twenty-one of the treated, and all 12 control children completed 5 years of follow-up.

Echo-Doppler evaluation was performed before $\mathrm{GH}$ therapy, and yearly for 2 years of GH therapy, as well as

Table 1 Clinical characteristics of the $\mathrm{GH}$-treated group and the control patients before $\mathrm{GH}$ therapy (mean \pm s.D.).

\begin{tabular}{lcc}
\hline & $\begin{array}{c}\text { GH treated } \\
(n=22)\end{array}$ & $\begin{array}{c}\text { Control } \\
(n=12)\end{array}$ \\
\hline Age (years) & $5.4 \pm 0.9$ & $5.1 \pm 1.0$ \\
Height (SDS) & $-2.6 \pm 0.4$ & $-2.4 \pm 0.4$ \\
BMI (SDS) & $-0.77 \pm 0.60$ & $-0.70 \pm 0.71$ \\
Growth velocity (SDS) & $-0.5 \pm 0.6$ & $-0.7 \pm 0.6$ \\
Peak serum GH $(\mu \mathrm{g} / \mathrm{l})$ & $14.9 \pm 3.7$ & $12.5 \pm 4.0$ \\
Serum IGF-I $(\mathrm{nmol} / \mathrm{l})$ & $20.1 \pm 8.9$ & $14.5 \pm 6.0$ \\
Serum IGFBP-3 $(\mathrm{mg} / \mathrm{l})$ & $3.4 \pm 0.7$ & $3.0 \pm 1.1$ \\
\hline
\end{tabular}

at 6 and 12 months after interruption of therapy. Left ventricular long- and short-axis $2 \mathrm{D}$-guided views were obtained. Apical four-chamber views were recorded (12). Heart rate, aortic and pulmonary valve area and flow integrals were determined to derive stroke volume and cardiac output. Results were normalized with respect to body surface area. Left ventricular dimensions were measured from left ventricular end-systolic and end-diastolic dimensions. Left ventricular wall width was measured in end-diastole, obtaining left ventricular (free) inferior wall and inter-ventricular septum dimensions. Aortic and pulmonary valve internal diameters served to calculate the respective valve areas. Valve area multiplied by its flow integral gave the stroke volume, which was multiplied by heart rate (per minute) to give cardiac output.

Serum GH was measured by a double antibody RIA kit (HGHK-2, Sorin Biomedica, Saluggia, Italy), with a sensitivity of $0.3 \mu \mathrm{g} / \mathrm{l}$ and intra- and interassay variability of 7.7 and $11 \%$ respectively. Serum IGF-I was measured by an RIA kit (Incstar Corp., Stillwater, MN, USA), with a sensitivity of $2 \mathrm{nmol} / \mathrm{l}$, and intra- and interassay variability of 8.4 and $10.3 \%$ respectively. Serum IGFBP-3 was measured by an IRMA kit (Diagnostic System Lab., Webster, TX, USA), with an intra- and interassay variability of 3.9 and $8 \%$ respectively.

The body mass index (BMI, $\mathrm{kg} / \mathrm{m}^{2}$ ) is expressed as SDS for age. Results are expressed as mean \pm s.D. Statistical significance was evaluated by a Student's $t$-test, and $P$ values of less than 0.05 were considered statistically significant.

\section{Results}

\section{Auxology}

Nineteen of the children completed 3 years of $\mathrm{GH}$ therapy and three children discontinued treatment as they reached the 25 th percentile after 30,30 and 33 months. During the first year of GH treatment, growth velocity accelerated from $-0.5 \pm 1.1$ SDS to $3.8 \pm$ 1.3 SDS (Fig. 1, upper panel). It decelerated to $1.7 \pm$ 1.0 SDS by the second year, and to $1.0 \pm 0.9$ SDS $(n=22)$ by the third year $(n=19)$. After GH withdrawal, growth decelerated in every child over the first 6 months to a velocity that was significantly lower than pretreatment values $(-2.9 \pm 1.9$ SDS, $P<0.05)$. It remained low at $-2.8 \pm 1.8$ SDS for the next year, and recovered to pretreatment velocity by the fourth semiannual measurement. Growth velocity of the control group remained unchanged and fluctuated between $-0.7 \pm 0.6$ SDS and $-1 \pm 1.4$ SDS. Height SDS increased in the treatment group from $-2.6 \pm 0.4$ SDS to $-1.0 \pm 0.3$ SDS at therapy interruption, and declined to $-1.6 \pm 0.4$ SDS in 2 years post treatment (Fig. 1, middle panel). Table 2 summarizes auxological data, including height predictions. Due to the young 

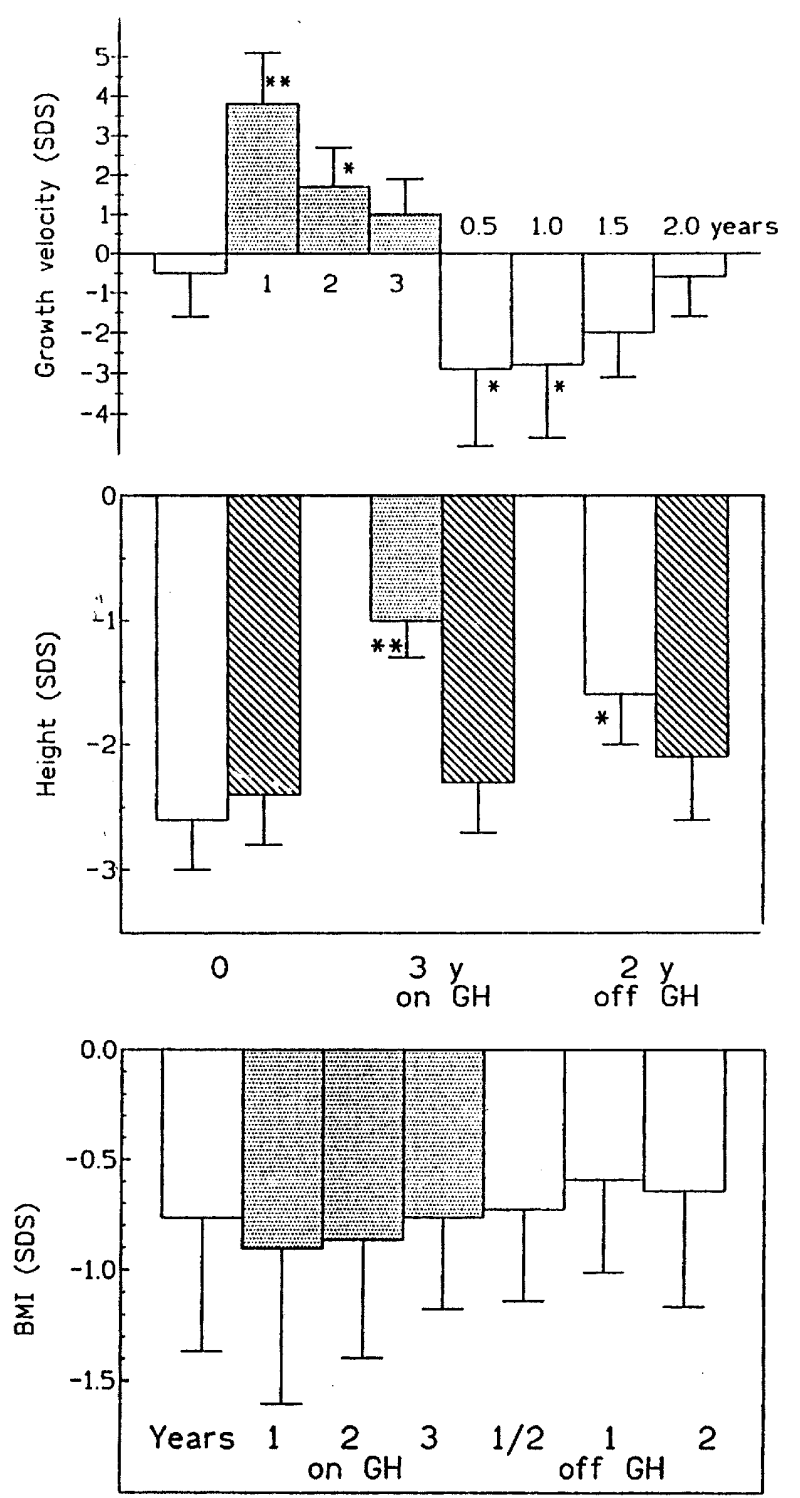

Figure 1 Auxological data in controls (hatched bars), during 3 years of GH therapy (dotted bars) in short normal children, and for 2 years after therapy discontinuation (open bars). Upper panel, growth velocity; middle panel, height; lower panel, BMI. Mean \pm S.D. ${ }^{\star} P<0.05,{ }^{* \star} P<0.01$ vs pretreatment.

age, it was not possible to calculate height predictions before therapy. The difference in predictions between treated and control children averaged $8 \mathrm{~cm}$ by the end of treatment $(P<0.001)$ and $5 \mathrm{~cm} 2$ years later $(P<0.01)$. The BMI on and off GH were not statistically different, but the trends were clear (Fig. 1, lower panel). On GH therapy BMI SDS decreased by the first year from a mean -0.77 to -0.91 . The effect waned by the second year $(-0.87)$ and disappeared by the third $(-0.76)$, thereby increasing by the second half year post therapy to levels that were higher than pretreatment $(-0.59)$.

\section{GH-IGF-I axis}

To evaluate the role of the GH-IGF-I axis during the growth deceleration, an arginine stimulation test $(0.5 \mathrm{~g} / \mathrm{kg})$ was performed in eight of the children 1 month after $\mathrm{GH}$ withdrawal, in five of the children 3 months and in ten of the children 6 months after $\mathrm{GH}$ withdrawal, and compared with pretreatment response by a paired $t$-test (Fig. 2). Peak GH was $14.9 \pm 3.7 \mu \mathrm{g} / \mathrm{l}$ before treatment, $9.7 \pm 3.5$ at 1 month, $12.3 \pm 5.4$ at 3 months, and $12.5 \pm 5.2$ at 6 months (not significant (NS) at all times). Serum IGF-I remained unchanged (Fig. 2), and was $20.1 \pm 8.9 \mathrm{nmol} / \mathrm{l}$ pretreatment, $21 \pm$ 7.9 at 1 month off treatment, $20.5 \pm 7$ at 3 months, and $18 \pm 4.2$ at 6 months (NS), and not different from control values. Serum IGFBP-3 remained unchanged (Fig. 2), and was $3.4 \pm 0.7 \mathrm{mg} / \mathrm{l}$ pretreatment, $3.2 \pm 0.4$ at 1 month post treatment, $3.7 \pm 0.5$ at 3 months and $3.4 \pm 1.3$ at 6 months (NS), and not different from control values.

\section{Bone maturation}

The bone age advanced over chronological age by a mean of 3.3/3 'years'/year during treatment, and by a further 1.8/2 'years'/year after GH withdrawal (Fig. 3, upper panel). Serum alkaline phosphatase increased from a pretreatment value of $188 \pm 18 \mathrm{U} / \mathrm{l}$ to $252 \pm 40$ at 2 years of GH treatment (NS), declined to $166 \pm$ $22 \mathrm{U} / \mathrm{l}$ at 6 months off $\mathrm{GH}(P<0.05)$, and normalized at 12 months post treatment at $215 \pm 56 \mathrm{U} / \mathrm{l}$ (Fig. 3, lower panel).

\section{Echocardiography}

Incomplete compliance of the control group with yearly echocardiography did not allow for meaningful summary of that group. End-systolic and end-diastolic left ventricular dimensions of the GH-treated group are shown in Fig. $4 \mathrm{~A}$ and $\mathrm{B}$. The diastolic diameter did not change during the 2 year course of GH therapy, but it fell significantly during the initial 6 months of $\mathrm{GH}$ withdrawal from $4.9 \pm 0.77$ to $3.8 \pm 0.13 \mathrm{~cm} / \mathrm{m}^{2}$ $(P<0.05)$, and remained low at $3.7 \pm 0.6 \mathrm{~cm} / \mathrm{m}^{2}$ by 12 months post therapy. Likewise, the systolic diameter did not change during GH therapy, and fell significantly during the initial 6 months of $\mathrm{GH}$ withdrawal from $2.9 \pm 0.17$ to $2.0 \pm 0.04 \mathrm{~cm} / \mathrm{m}^{2}(P<0.01)$, to normalize at $2.6 \pm 0.6 \mathrm{~cm} / \mathrm{m}^{2}$ by 12 months post therapy. Resting cardiac output was calculated from pulmonary and aortic stroke volumes and heart rates. Pulmonary output (Fig. 4C) did not change during the 2 years of $\mathrm{GH}$ therapy, but fell during the initial 6 months of $\mathrm{GH}$ withdrawal from $4.3 \pm 2$ to $3.1 \pm 0.9 \mathrm{l} / \mathrm{min}$ per $\mathrm{m}^{2}$ $(P<0.01)$, and remained low at $3.2 \pm 1.1 \mathrm{l} / \mathrm{min}$ per $\mathrm{m}^{2}$ by 12 months post therapy $(P<0.01)$. The aortic cardiac output (Fig. 4D) did not change during $\mathrm{GH}$ therapy, fell significantly during the initial 6 months of $\mathrm{GH}$ withdrawal from $5.3 \pm 1.8$ to $4.3 \pm 0.95 \mathrm{l} / \mathrm{min}$ per 
Table 2 Summary of auxology before GH treatment, at the end of treatment and 2 years after $\mathrm{GH}$ therapy. Growth velocity data relate to the most recent 6 month period. Adult height predictions were done by the TW-2 method (13), and, due to the young age, were not possible before treatment. Mean \pm S.D. .

\begin{tabular}{lcc}
\hline & GH treated & Control \\
\hline Pretreatment & & \\
Height (SDS) & $-2.6 \pm 0.4$ & $-2.4 \pm 0.4$ \\
Growth velocity (SDS) & $-0.5 \pm 0.6$ & $-0.7 \pm 0.6$ \\
$\quad$ Bone age - calendar age (years) & $-1.1 \pm 0.4$ & $-1.0 \pm 0.5$ \\
End of treatment & & \\
$\quad$ Height (SDS) & $-1.0 \pm 0.3^{* * *}$ & $-2.2 \pm 0.5$ \\
$\quad$ Growth velocity (SDS) & $1.0 \pm 0.9$ & $-1.0 \pm 0.4$ \\
$\quad$ Bone age - calendar age (years) & $-0.9 \pm 0.8^{\star *}$ & $-1.9 \pm 0.6$ \\
$\quad$ Height prediction (cm) & $164 \pm 5^{\star * *}$ & $156 \pm 3$ \\
Two years after treatment & & \\
$\quad$ Height (SDS) & $-1.6 \pm 0.4^{*}$ & $-2.0 \pm 0.6$ \\
$\quad$ Growth velocity (SDS) & $-0.6 \pm 0.9$ & $-1.0 \pm 1.4$ \\
$\quad$ Bone age - calendar age (years) & $-1.3 \pm 0.9^{*}$ & $-2.0 \pm 0.8$ \\
Height prediction (cm) & $166 \pm 4^{\star *}$ & $161 \pm 3$ \\
\hline
\end{tabular}

${ }^{*} P<0.05 ;{ }^{* *} P<0.01 ;{ }^{* \star *} P<0.001$ vs control.

$\mathrm{m}^{2}(P<0.01)$, and remained low at $4.3 \pm 0.89 \mathrm{l} / \mathrm{min}$ per $\mathrm{m}^{2}$ by 12 months post therapy $(P<0.01)$. The patients and parents denied any symptoms that might be related to cardiac insufficiency.

\section{Discussion}

Based on our previous results showing a pivotal role of age in the outcome of GH therapy (10), the protocol of the present study included interruption of therapy at a prepubertal age. It was hoped that it would prevent pubertal initiation and shortening, and the accompany- ing bone age acceleration reported by us and others (10). Under these conditions, every single child increased its growth rate. In fact, at the end of $\mathrm{GH}$ therapy, mean height prediction of the treated group was $8 \mathrm{~cm}$ higher than control. It is the deceleration of the patients' growth after GH withdrawal that constitutes the focus of the present report. Deceleration of growth was observed in every child in this group of patients. Its magnitude was striking, and it lasted for as long as 18 months. At that time, the children were 7 to 11.3 years old and still prepubertal $(31 / 33$, two girls just started Tanner breast stage 2). Despite
Peak GH

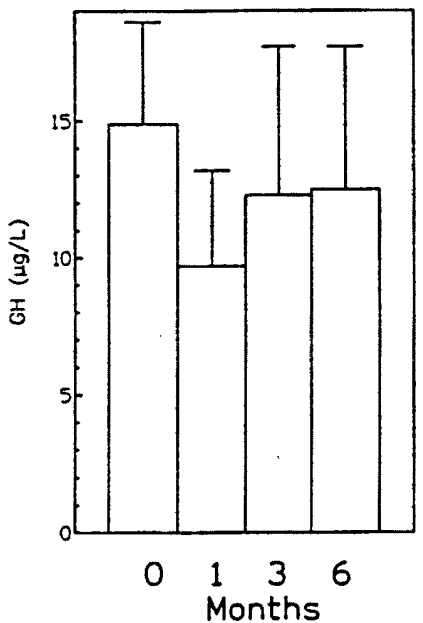

IGF-I

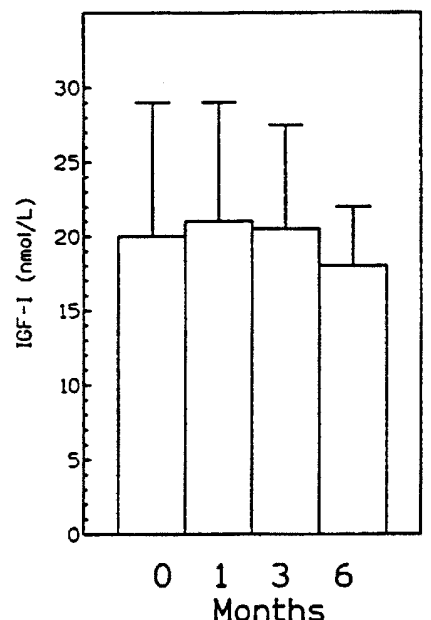

IGFBP $_{3}$

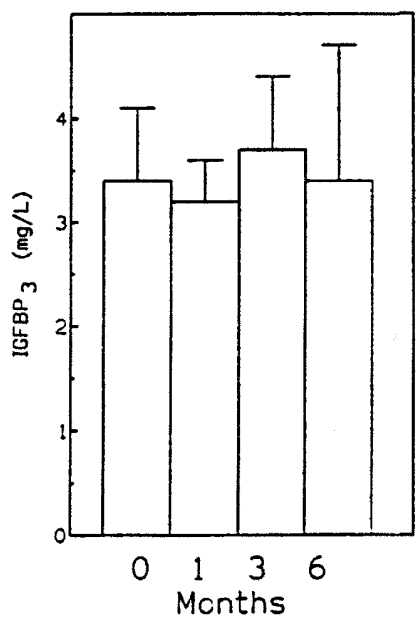

Figure 2 Endocrine data after GH discontinuation in short normal children. Left panel, GH peak value after $0.5 \mathrm{~g} / \mathrm{kg}$ arginine; middle panel, plasma IGF-I; right panel, serum IGFBP-3. Mean \pm s.D. 

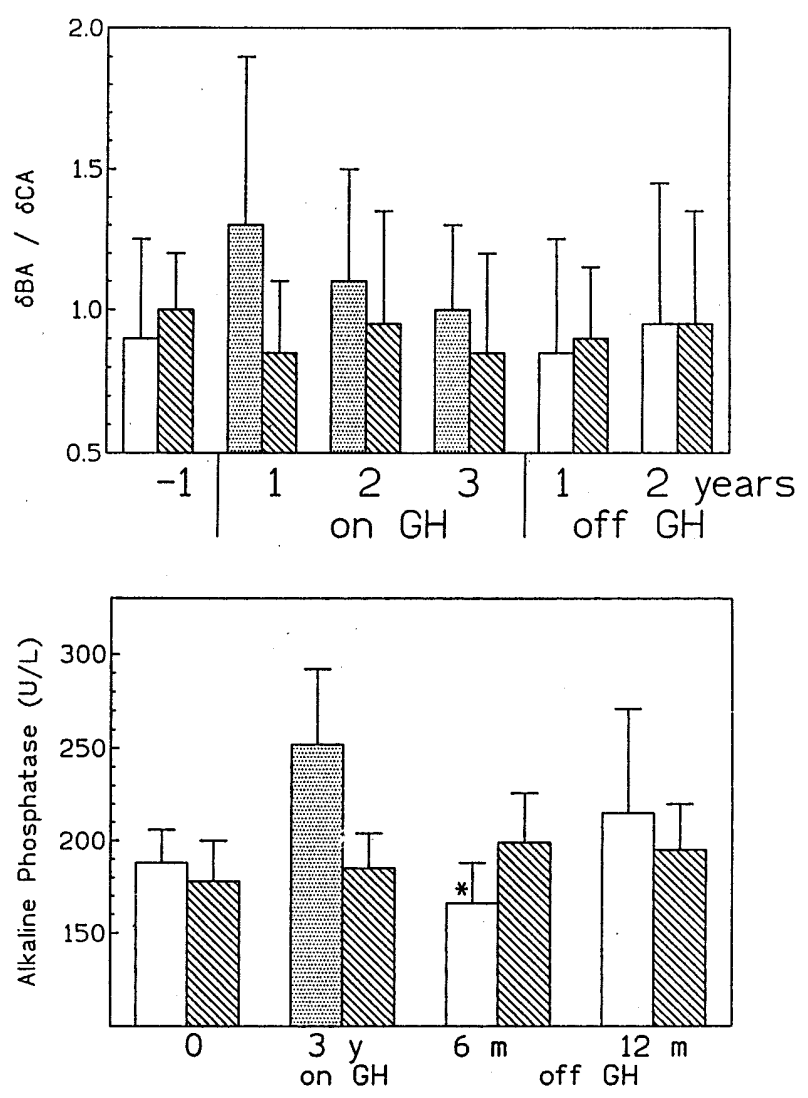

Figure 3 Bone maturation (upper panel) and serum alkaline phosphatase (lower panel) in the control group (diagonal bars) and in the GH-treated group during 3 years of GH therapy (dotted bars) and after GH withdrawal (open bars). Mean \pm s.D. $\delta \mathrm{BA} / \delta \mathrm{CA}$ bone age advanced over calendar age advancement. ${ }^{*} P<0.05$ vs 3 y $\mathrm{GH}$.

deceleration, mean height prediction calculated 2 years after withdrawal was still $5 \mathrm{~cm}$ taller than control and statistically significant. This may be related to the simultaneous deceleration of bone maturation.

Little has been reported on the outcome of $\mathrm{GH}$ treatment in ISS after treatment withdrawal. Tanner et al. (14) reported on deceleration of growth after $\mathrm{GH}$ therapy for 6-12 months. Raiti et al. (4) identified a subgroup of patients with deceleration of growth after 6 months of GH therapy, and characterized them as short normal with greater pretreatment growth velocity than the others. Chalew et al. (15) observed deceleration of growth in 5 out of 11 patients. Ackland et al. (16) showed a fall in growth velocity to pretreatment values after 6 months of GH therapy and did not observe any deceleration of growth. The discrepancy of results with the present report, where all children showed deceleration of growth, seems to rest with the daily GH dose for a much longer treatment period. Apparently the withdrawal deceleration of growth is time dependent and more pronounced after prolonged GH treatment. The dose used in the present study was similar (14) or lower than the other reports $(4,15,16)$. It was given by us as
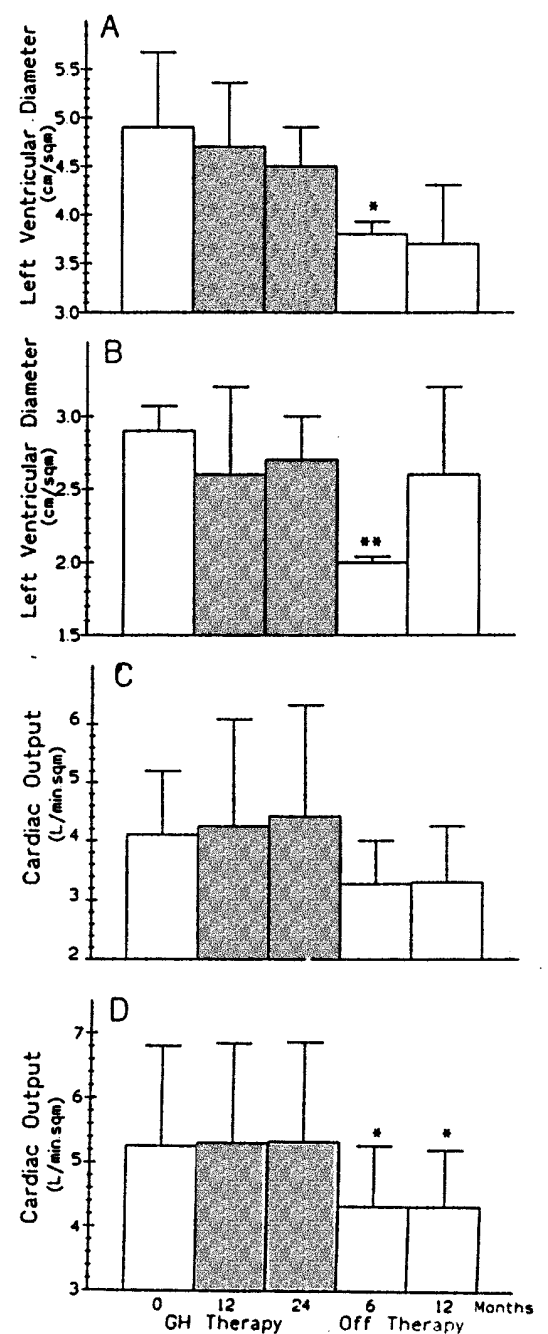

Figure 4 Echocardiographic findings before, during 2 years of $\mathrm{GH}$ therapy (shaded bars) and off therapy (open bars). (A) Systolic left ventricular diameter. (B) Diastolic left ventricular diameter. (C) Cardiac output calculated for the pulmonary artery. (D) Cardiac output calculated for the aorta. Mean \pm S.D. ${ }^{*} P<0.05$, ${ }^{* *} P<0.01$ vs pretreatment.

a daily subcutaneous injection and as 3 times weekly intramuscular $(14)$ or subcutaneous $(15,16)$ injections in the previous reports. In the mechanism of deceleration of growth the dose is, therefore, of no importance, but the daily schedule of injections might be meaningful.

A similar tendency was observed for BMI, alkaline phosphatase and heart measurements, but the number of observations were too small to reach statistical significance in variables that vary so widely among children.

Cardiac effects of GH have been known from studies of GHD (17) and of acromegaly (18). It has been shown that $\mathrm{GH}$ administration normalizes cardiac performance in GH-deficient patients (19). After 2 years of GH therapy in ISS we observed no increase in resting 
cardiac output that decreased post therapy to values that were lower than those observed before treatment or in the control group, but well within the normal range. The reduction in left ventricular size during the $\mathrm{GH}$ withdrawal period was accompanied by a corresponding reduction in cardiac output. From a consumption point of view the post-therapy decline seems advantageous, with a reduction of left ventricular dimensions and reduced cardiac output. These changes were observed at rest and did not manifest clinically. None of the patients had signs or symptoms of decompensation. The impact on exercise performance has not been evaluated, as it was felt that these patients were too young and of too small body size for a study of myocardial reserve under ergometric conditions.

Thus, GH treatment was associated in these children with development of a physical adaptation to continuous high serum levels of $\mathrm{GH}$, and hence signs of tolerance followed by a withdrawal syndrome can indicate GH dependence. Waning of the growth promoting effect during treatment and subsequent recovery by increasing GH doses are well known further manifestations of drug dependence. The most obvious symptom is growth arrest for a period that apparently depends on the treatment duration and schedule. An increase in fat mass, a decrease in metabolic rate and a decline in resting cardiac output have been reported. Previously, Rudman et al. (20) showed in GH-deficient patients a rapid development of negative balances of nitrogen, phosphorus, sodium, and potassium immediately after GH withdrawal. By the end of a year of therapy, GH lost its anabolic effect, which was restored only after tripling the $\mathrm{GH}$ dose, and therapy ended in a catabolic state that was worse than pretreatment values. $\mathrm{GH}$ has been proposed to improve muscle performance, relative volume contraction, sleep, vitality, well-being and overall quality of life. All these actions may manifest themselves in the withdrawal syndrome and require further evaluation.

The mechanism by which chronic drug exposure elicits GH dependence and withdrawal effects is unclear. During the nadir of growth velocity, peak serum GH levels were normal, as were serum IGF-I and IGFBP-3 levels. Although spontaneous secretion of $\mathrm{GH}$ was not measured, normal levels of IGF-I and IGFBP-3 reflect an intact GH-IGF-I axis. Indeed, it was reported that exogenous GH therapy for as long as 12 months did not interfere with the endogenous pulsatile secretion of $\mathrm{GH}$ $(16,21)$, although these two protocols used 3 times weekly GH injections. Subcutaneous administration of daily GH results in an unphysiological serum GH profile, with peak levels at $4 \mathrm{~h}$, and slow disappearance over the course of $12-24 \mathrm{~h}$. This pattern can be regarded as continuous administration of $\mathrm{GH}$, rather than the physiological pulses, with a frequency of eight per day. As previously observed in short term studies, alternate day therapy, which in a normal child would allow for normal GH pulsatility in the interval day, resulted in zero or minimal deceleration of growth. Moreover, $\mathrm{GH}$ doses used in therapy stimulate IGF-I to reach supra-physiological serum levels. The mechanism seems, therefore, to rest with GH and IGF-I action at target tissues of the growing bone and the heart. By analogy with other models of long term memory and long term drug addiction and abstinence (22), such long lived adaptations involve relative stable changes in molecular switches, and transcription factors have been implicated in persistent drug-induced plasticity. These mechanisms may affect stem cells destined to differentiate into proliferating cells, such as cartilage cells, through signal mechanisms of GH and IGF-I receptors. It is concluded that the first 2 years of $\mathrm{GH}$ treatment contribute significantly to adult height prediction, and the third year does not, as previously reported for older children (10). Treatment of the young child is more economical and may have a better outcome, but the final height of these children is presently unknown. The withdrawal deceleration of growth seems to be related to daily GH injections for a long period, and resolves by the second post-treatment year. This is the first report of cardiac manifestations of GH withdrawal. The mechanism of $\mathrm{GH}$ withdrawal symptoms are presently unknown, but they are not induced by alterations of serum GH or IGF-I.

\section{References}

1 Allen DB, Brook CGD, Bridges, NA, Hindmarsh PC, Guyda HJ \& Frazier D. Therapeutic controversies: growth hormone $(\mathrm{GH})$ treatment of non-GH deficient subjects. Journal of Clinical Endocrinology and Metabolism 199479 1239-1248.

2 Frazer TE, Gavin VR, Baughaday WH, Hillman RE \& Weldon VV. Growth hormone-dependent growth failure. Journal of Pediatrics $198210112-15$.

3 Van Vliet G, Styne DM, Kaplan SL \& Grumbach MM. Growth hormone treatment for short stature. New England Journal of Medicine 1983309 1016-1022.

4 Raiti S, Kaplan SL, Van Vliet G, Moore WV \& The National Hormone and Pituitary Program Growth Hormone Committee. Short-term treatment of short stature and subnormal growth rate with human growth hormone. Journal of Pediatrics 1987110 357-361.

5 Hopwood NJ, Hintz RL, Gertner JM, Attie KM, Johanson AJ, Baptista J et al. Growth response of non-growth hormone deficient children with marked short stature during three years of growth hormone therapy. Journal of Pediatrics 1993123 215-222.

6 Loche S, Cambiaso P, Setzu S, Carta D, Marini R, Borrelli P et al. Final height after growth hormone therapy in non-growth hormone deficient children with short stature. Journal of Pediatrics 1994125 196-200.

7 Wit JM, Boersma B, de Muinck Keizer-Schrama SM, Nienhuis HE, Oostdijk W, Otten BJ et al. Long-term results of growth hormone therapy in children with short stature, subnormal growth rate and normal growth hormone response to secretagogues. Dutch Growth Hormone Working Group. Clinical Endocrinology 199542 365-372.

8 Zadik Z, Chalew S, Zung A, Landau H, Leiberman E, Koren R et al. Effect of long term growth hormone therapy on bone age and pubertal maturation in boys with and without classical growth hormone deficiency. Journal of Pediatrics 1994125 189-195.

9 Hintz RL, Attie KM, Johanson AJ, Baptista J, Roche AF \& The Genentech Study Group. Near final height in GH-treated short 
children without classical GH deficiency. Pediatric Research 1995 37 A530.

10 Hochberg Z, Leiberman E, Landau H, Koren R \& Zadik Z. Age as a determinant of the impact of growth hormone therapy on predicted adult height. Clinical Endocrinology $199441331-335$.

11 Sacca L, Cittadini A \& Fasio S. Growth hormone and the heart. Endocrine Reviews 199415 555-573.

12 Sahn DJ, DeMaria A, Kisslo J \& Weyman A. Recommendations regarding quantitation in M-mode echocardiography: results of a survey of echocardiographic measurements. Circulation 197858 1072-1083.

13 Tanner JM, Whitehouse RH, Cameron N, Marshall WA, Healy MJR \& Goldstein H. Assessment of Skeletal Maturity and Prediction of Adult Height (TW-2 Method), 2nd edn. London: Academic Press, 1983.

14 Tanner JM, Whitehouse RH, Hughes PCR \& Vince FP. Effect of human growth hormone treatment for 1 to 7 years on the growth of 100 children with growth hormone deficiency, low birth weight, inherited smallness, Turner's syndrome and other complaints. Archives of Disease in Childhood 197146 745-782.

15 Chalew SA, Raiti S, Armour KM \& Kowarski AA. Therapy of short children with subnormal integrated concentrations of growth hormone. American Journal of Disabled Children $19871411195-$ 1198.

16 Ackland FM, Jones J, Buckler JMH, Dunger DB, Rayner PHW \& Preece MA. Growth hormone treatment in non-growth hormonedeficient children: effects of stopping treatment. Acta Pediatrica Scandinavica 1990366 (Suppl) 32-37.
17 Merola B, Cittadini A, Colao A, Loimgobardi S, Fazio S, Sabatini D et al. Cardiac structural and functional abnormalities in adult patients with growth hormone deficiency. Journal of Clinical Endocrinology and Metabolism 199377 1658-1661.

18 Thuesen L, Christensen SE, Weeke J, Orskov H \& Henningsen P. A hyperkinetic heart in uncomplicated active acromegaly: explanation of hypertension in acromegalic patients? Acta Medica Scandinavica 1988223 237-243.

19 Cittadini A, Cuocolo A, Merola B, Fazio S, Sabatini D, Nicolai E et al. Impaired cardiac performance in GH-deficiency adults and its improvement after GH replacement. American Journal of Physiology 1994267 E219-E225.

20 Rudman D, Patterson JH \& Gibbas DL. Responsiveness of growth hormone deficient children to human growth hormone. Journal of Clinical Investigation 197352 1108-1112.

21 Wu RHK, St Louis Y, DiMartino-Nardi J, Wesoly S, Sobel EH, Sherman B et al. Preservation of physiological growth hormone (GH) secretion in idiopathic short stature after recombinant GH therapy. Journal of Clinical Endocrinology and Metabolism 199070 1612-1616.

22 Nestler EJ \& Aghajania GK. Molecular and cellular basis of addiction. Science 1997278 58-63.

Received 28 July 1997

Accepted 5 January 1998 